\title{
Selection of Soft Asphalt Pavements for Low-volume roads in Lithuania
}

\author{
Viktoras Vorobjovas ${ }^{\mathrm{a}}$, Tadas Andriejauskas ${ }^{\mathrm{a}}$, Zigmantas Perveneckas ${ }^{\mathrm{b}}$ \\ ${ }^{a}$ Road Research Institute, Vilnius Gediminas Technical University, Linkmenu str. 28, LT-08217 Vilnius, Lithuania \\ ${ }^{b}$ Lithuanian Road Administration, J. Basanaviciaus str. 36/2, LT-03109 Vilnius, Lithuania
}

\begin{abstract}
In Lithuania pavement structure of low-volume roads satisfy the 6th class according to normative documents where annual average daily traffic is up to 500 vehicles per day. According to normative documents the thickness of pavement frost resistance structure is reduced. But in winters of 2010/2011 and 2011/2012 a very high freezing index was observed. It led to frost heaving, cracking, loss of bearing capacity and numerous defects in spring. Preliminary investigations showed the need to pay attention to the top $30 \mathrm{~cm}$ of subgrade, which has to be constructed with low frost sensitive soils or need treatment. These additional works would significantly increase the road construction costs up to $25 \%$. As an alternative solution the use of soft asphalt pavements was proposed. This technology is widely used in Nordic countries. But in Lithuania it has never been applied. Research on the designed soft asphalt mixtures was carried. Also, it was proposed the recommendation for soft asphalt pavement structure for low-volume roads in Lithuania.
\end{abstract}

Keywords: low-volume roads; soft asphalt; soft bituminous binder.

\begin{tabular}{|ll|}
\hline Nomenclature \\
A & design load \\
FI & freezing index \\
AADT & average annual daily traffic \\
vpd & vehicles per day \\
\hline
\end{tabular}

\section{Introduction}

In 2012 regional roads made $68.6 \%$ of the total number of roads of national significance. $52.2 \%$ of regional roads have gravel pavement and $35.8 \%$ of the total road network of Lithuania is comprised by gravel roads [1]. Vehicle flow on the Lithuanian low-volume roads with gravel pavement from 2000 to 2009 was rapidly increasing. Therefore deficiencies in the road infrastructure of national significance became more and more apparent as the gravel roads did not comply with the requirements established, i.e. their characteristics did not meet the requirements to the pavement structure of appropriate technical road category [2-5].

The best method to improve driving conditions and quality of life for the residents living close to the gravel roads is to replace the old gravel pavement with the new asphalt pavement. Thus, these roads must be well planned, well designed, well-constructed and properly maintained to minimize adverse effects, to be cost-effective in the long term and to have acceptable maintenance and repair costs [6]. However, when preparing the design for a gravel road reconstruction the selection of proper materials for a structural pavement layers should be secured. Designers, having received a request from the customers, are also encouraged to design a cost-efficient pavement structure. Therefore, the old gravel pavement, without making any investigations, is often assumed as a frost-blanket course to be covered with a levelling gravel layer. And the levelling gravel pavement is covered with a crushed stone/gravel base course and asphalt pavement layers.

The class of road pavement structure, its structural layers and their thicknesses are selected in accordance with "the Design Specifications for the Standardized Road Pavement Structures KPT SDK 07" (KPT SDK 07). When reconstructing gravel roads a single-layer pavement structure is mostly selected with the layer thickness of $6 \mathrm{~cm}$ or $10 \mathrm{~cm}$ depending on the design load A. As a result after the reconstruction of gravel road the pavement structure is not only thickened inconsiderably but also strengthened insufficiently. However having paved gravel roads they are more often used by transit traffic due to

Corresponding author: Viktoras Vorobjovas. E-mail address: viktoras.vorobjovas@vgtu.lt

http://dx.doi.org/10.3846/enviro.2014.177

(C) 2014 The Authors. Published by VGTU Press. This is an open-access article distributed under the terms of the Creative Commons Attribution License, which permits unrestricted use, distribution, and reproduction in any medium, provided the original author and source are credited. 
the low traffic volume and good driving conditions. Therefore the deformations start to form in the $4^{\text {th }}-5^{\text {th }}$ year of the service life of reconstructed gravel road.

Pavement structure of the low-volume roads with the annual average daily traffic (AADT) lower than $200 \mathrm{vpd}$ corresponds to the pavement structure of $6^{\text {th }}$ class which according to the normative documents is laid with a lower safety factor, i.e., of reduced thickness (55-65 cm according to KPT SDK 07). After recent winters in Lithuania, when the total freezing index (FI) was high, it was observed that in spring on the low-volume roads with asphalt pavement the extent of frost heaves has increased and more pavement defects have occurred. In order to avoid frost heaves a special attention should be paid to the $30 \mathrm{~cm}$ thick upper subgrade which should be laid from less frost-sensitive soils or it is necessary to carry out the soil improvement or strengthening. Those additional works would significantly increase road construction costs (up to $25 \%$ ). Over the last decade on the low-volume roads of Nordic countries the soft asphalt has been used which is less sensitive to frost heaves and fatigue, more flexible and has the ability of self-healing.

\section{Literature review}

Soft asphalt is commonly made from mineral material mixture, filler aggregate and binder - soft bitumen. The soft asphalt mixture uses bitumen of high penetration from 250/330 to 650/900 or soft bitumen from V1500 to V12000. The largest experience of using soft bitumen has been represented by Finland, Sweden and Germany. The technical documents of Finland, Sweden and Germany give requirements to the soft bitumen. The Swedish General Technical Construction Specification for Roads Road 94 indicates that on roads with the annual average daily traffic $\leq 500$ vpd the surface- wearing course can be laid on gravel pavement. However, this type of pavement structure should meet the requirements to layer thicknesses.

Safwat has carried out a research on low-volume roads (AADT $\leq 1500 \mathrm{vpd}$ ) where the surface course was laid from $83 \%$ of used asphalt granules, $14 \%$ of new mineral materials and $3 \%$ of new bitumen emulsion mixture produced on a basis of soft bitumen of different viscosity [7]. The research determined that after 7 years of road service life the extent of pavement distresses was inconsiderable and the studied cold-mix asphalt mixtures can be an alternative to hot-mix asphalt mixtures. On a basis of research carried out by Jacobson the test procedures for cold-mix asphalt mixtures were prepared. These procedures were included in the directives for cold recycling products of the Swedish National Road Administration [8]. Jacobson with the co-authors used to determine physical and mechanical properties of soft asphalt specimens taken from low-volume roads [9]. The research has determined that asphalt cores can be taken from the pavement not earlier than 1 year after the road was opened to traffic. Only then it is possible to determine the stability and stiffness modulus of the specimens. The research has showed that mechanical properties of soft asphalt may vary depending on its service life, composition and production process. Viscosity of the regenerated bitumen binder may vary from $12000 \mathrm{~mm}^{2} / \mathrm{s}$ (just after laying asphalt mixture) to $33000 \mathrm{~mm}^{2} / \mathrm{s}$ (after three service years). Jacobson with the co-authors states that when defining mechanical properties of soft asphalt it is very important to select properly the testing temperatures depending on a climatic zone where the test soft asphalt mixture is laid [10].

Having studied the technical documents of various European countries the following advantages of soft asphalt are distinguished: elastic; durable; self-healing; low temperature mixing; well workable; recyclable.

Also, soft asphalt has some disadvantages: not stable enough; it could form water film on new constructed asphalt pavement; low light reflection; flux used for binder is environmentally unfriendly; limited resistance to abrasion.

The European Standard EN 13108-3 "Bituminous mixtures. Material specifications. Part 3: Soft Asphalt" specifies requirements for soft asphalt used on the roads and other trafficked areas. According to the standard EN 13108-3 there are several types of soft asphalt (type A; type B; type C; type S). As the aim of further research was to use as softer and reasonable bitumen as possible, it was selected soft asphalt of the types $\mathrm{C}$ and $\mathrm{S}$.

\section{The object and test methods}

The research was performed in Vilnius Gediminas Technical University, Road Research Institute. Soft asphalt mixtures of two fractions $0 / 11$ and $0 / 16$ of aggregates were mixed with two different bituminous binders accordingly V6000 and V12000. Two types of crushed dolomite were selected. In the first case the aggregate consisted of $100 \%$ of crushed particles and of $70 \%$ of crushed particles with $30 \%$ of round particles $(<2 \mathrm{~mm})$ in the second one. The particle size distribution of aggregate was selected according to the standard EN 13108-3 and its tables 3a (soft asphalt type C) and 4a (soft asphalt type $\mathrm{S})$.

The ready-produced paving bitumen V12000 was used, i.e., obtained from the manufacturer, whereas, paving bitumen V6000 was produced in the laboratory by mixing bitumen of 160/220 grade bitumen with $8 \%$ of flux oil Iteroil G40.

The research of affinity between aggregate and bitumen showed that optimum amount of adhesion additive Iterlene $\mathrm{IN} / 400-\mathrm{L}$ agent is $0.5 \%$ by mass of bituminous binder when mixing soft asphalt type $\mathrm{C}$. Thus, it was found that the optimum amount of adhesion additive Iterlene IN/400-L agent is $1.5 \%$ by mass of bituminous binder when mixing soft asphalt type $\mathrm{S}$.

Based on the above mentioned criteria 16 different soft asphalt mixtures were designed and mixed in the laboratory (Table 1). 
Table 1 Combination of soft asphalt mixtures

\begin{tabular}{|c|c|c|c|c|c|c|}
\hline $\begin{array}{l}\text { Type of } \\
\text { mineral } \\
\text { material }\end{array}$ & $\begin{array}{l}\text { The maximum } \\
\text { size of aggregate } \\
\text { particle, } \mathrm{mm}\end{array}$ & $\begin{array}{l}\text { Ratio of crushed } \\
\text { and round particles } \\
(<2.0 \mathrm{~mm})\end{array}$ & $\begin{array}{l}\text { Type of soft asphalt } \\
\text { (temperature of } \\
\text { mixture) }\end{array}$ & $\begin{array}{l}\text { Type of } \\
\text { bituminous } \\
\text { binder }\end{array}$ & $\begin{array}{l}\text { Amount of adhesive } \\
\text { additive (from } \\
\text { bituminous binder } \\
\text { mass) }\end{array}$ & Code of sample \\
\hline \multirow[t]{4}{*}{ Dolomite } & \multirow[t]{4}{*}{$0 / 11$} & \multirow[t]{4}{*}{$100 / 0$} & $\mathrm{C}\left(110^{\circ} \mathrm{C}\right)$ & V6000 & \multirow[t]{2}{*}{$0.5 \%$} & SA 11-d-V6000 type C (100 cr.) \\
\hline & & & $\mathrm{C}\left(115^{\circ} \mathrm{C}\right)$ & V12000 & & SA 11-d-V12000 type C (100 cr.) \\
\hline & & & $\mathrm{S}\left(75-90^{\circ} \mathrm{C}\right)$ & V6000 & \multirow[t]{2}{*}{$1.5 \%$} & SA $11-0-V 6000$ type S (100 cr.) \\
\hline & & & $\mathrm{S}\left(80-110^{\circ} \mathrm{C}\right)$ & V12000 & & SA $11-0-\mathrm{V} 12000$ type $\mathrm{S}(100 \mathrm{cr}$ ) \\
\hline \multirow{4}{*}{$\begin{array}{l}\text { Mix of } \\
\text { dolomite } \\
\text { and sand }\end{array}$} & & \multirow[t]{4}{*}{$70 / 30$} & $\mathrm{C}\left(110^{\circ} \mathrm{C}\right)$ & V6000 & \multirow[t]{2}{*}{$0.5 \%$} & SA $11-d-V 6000$ type $C$ (70 cr.) \\
\hline & & & $\mathrm{C}\left(115^{\circ} \mathrm{C}\right)$ & V12000 & & SA $11-d-V 12000$ type C (70 cr.) \\
\hline & & & $\mathrm{S}\left(75-90^{\circ} \mathrm{C}\right)$ & V6000 & \multirow[t]{2}{*}{$1.5 \%$} & SA $11-0-V 6000$ type $S(70 \mathrm{cr}$.) \\
\hline & & & $\mathrm{S}\left(80-110^{\circ} \mathrm{C}\right)$ & V12000 & & SA $11-0-V 12000$ type S (70 cr.) \\
\hline \multirow[t]{4}{*}{ Dolomite } & \multirow[t]{8}{*}{$0 / 16$} & \multirow[t]{4}{*}{$100 / 0$} & $\mathrm{C}\left(110^{\circ} \mathrm{C}\right)$ & V6000 & \multirow[t]{2}{*}{$0.5 \%$} & SA 16-d-V6000 type C (100 cr.) \\
\hline & & & $\mathrm{C}\left(115^{\circ} \mathrm{C}\right)$ & V12000 & & SA 16-d-V12000 type C (100 cr.) \\
\hline & & & $\mathrm{S}\left(75-90^{\circ} \mathrm{C}\right)$ & V6000 & \multirow[t]{2}{*}{$1.5 \%$} & SA 16-o-V6000 type S (100 cr.) \\
\hline & & & $\mathrm{S}\left(80-110^{\circ} \mathrm{C}\right)$ & V12000 & & SA $16-0-\mathrm{V} 12000$ type S (100 cr.) \\
\hline \multirow{4}{*}{$\begin{array}{l}\text { Mix of } \\
\text { dolomite } \\
\text { and sand }\end{array}$} & & \multirow[t]{4}{*}{$70 / 30$} & $\mathrm{C}\left(110^{\circ} \mathrm{C}\right)$ & V6000 & \multirow[t]{2}{*}{$0.5 \%$} & SA 16-d-V6000 type C (65 cr.) \\
\hline & & & $\mathrm{C}\left(115^{\circ} \mathrm{C}\right)$ & V12000 & & SA 16-d-V12000 type C (65 cr.) \\
\hline & & & $\mathrm{S}\left(75-90^{\circ} \mathrm{C}\right)$ & V6000 & \multirow[t]{2}{*}{$1.5 \%$} & SA $16-0-V 6000$ type $S$ ( $70 \mathrm{cr}$.) \\
\hline & & & $\mathrm{S}\left(80-110^{\circ} \mathrm{C}\right)$ & V12000 & & SA 16-o-V12000 type S (70 cr.) \\
\hline
\end{tabular}

The following physical and mechanical properties were determined for soft asphalt mixtures and their specimens produced in the laboratory:

- stability and flow by Marshall, according to the standard EN 12697-34;

The standard EN 12697-34 indicates that the test shall be performed at $60^{\circ} \mathrm{C}$, but the experience of foreign countries shows that the test temperature should be reduced to $40^{\circ} \mathrm{C}$. Therefore, the Marshall test was performed at $40^{\circ} \mathrm{C}$;

- indirect tensile strength, according to the standard EN 12697-23;

- water sensitivity, according to the standard EN 12697-12;

- maximum density of bituminous mixture, according to the standard EN 12697-5;

- bulk density of bituminous specimens, according to the standard EN 12697-6;

- air void content of bituminous specimens, according to the standard EN 12697-8.

\section{Analysis and evaluation of investigation results}

Experimental testing of the stability by Marshall showed that the stability varies from $6.7 \mathrm{kN}$ (SA 11-d-V6000 type C $(100 \mathrm{cr}$.)) to $10.6 \mathrm{kN}$ (SA 16-o-V6000 type C $(70 \mathrm{cr}$.)) (Fig. 1). It was determined that the stability of soft asphalt mixtures, in which the aggregate was made of $100 \%$ of crushed particles, is higher than that of the same type of soft asphalt mixture in which the aggregate was made of $\leq 70 \%$ of crushed particles. Comparing soft asphalt mixtures of type $\mathrm{C}$ and $\mathrm{S}$ it was determined that the stability of soft asphalt mixture of type $\mathrm{C}$ is higher than that of soft asphalt mixture of type S. Studying the relationship between the stability of soft asphalt mixtures and the type of bituminous binder it was determined that the stability of soft asphalt mixtures of type C, in which the bituminous binder V6000 was used, is higher than that of mixtures in which the bituminous binder V12000 was used. In soft asphalt mixtures of type S the determined stability was vice versa, though the difference itself is not large the stability is higher when using bituminous binder V12000. In this case the air void content is not the influencing property, since the air void content in soft asphalt mixtures of type $\mathrm{S}$ varies from $6.3 \%$ to 9.1\%. The results of the stability and flow of soft asphalt mixtures are given in Fig. 1 and Fig. 2. 


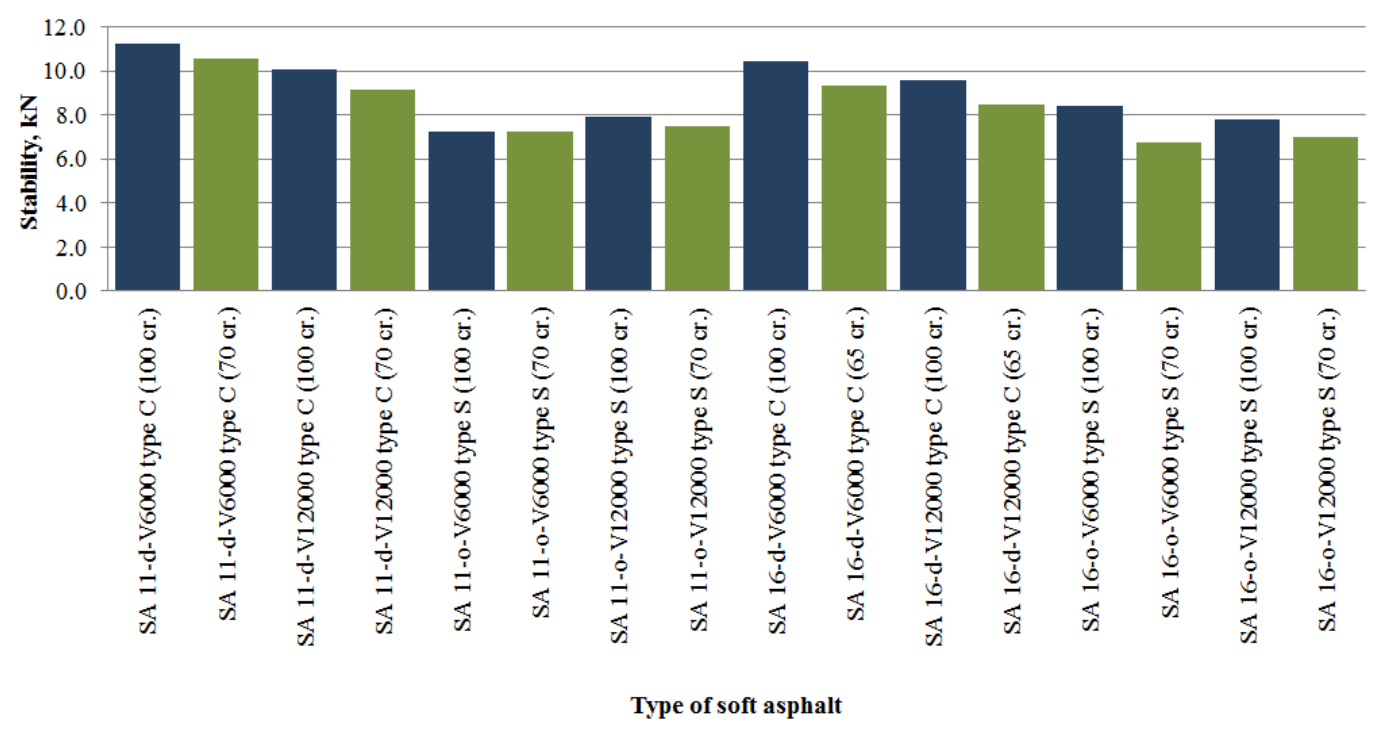

Fig. 1. Stability of soft asphalt

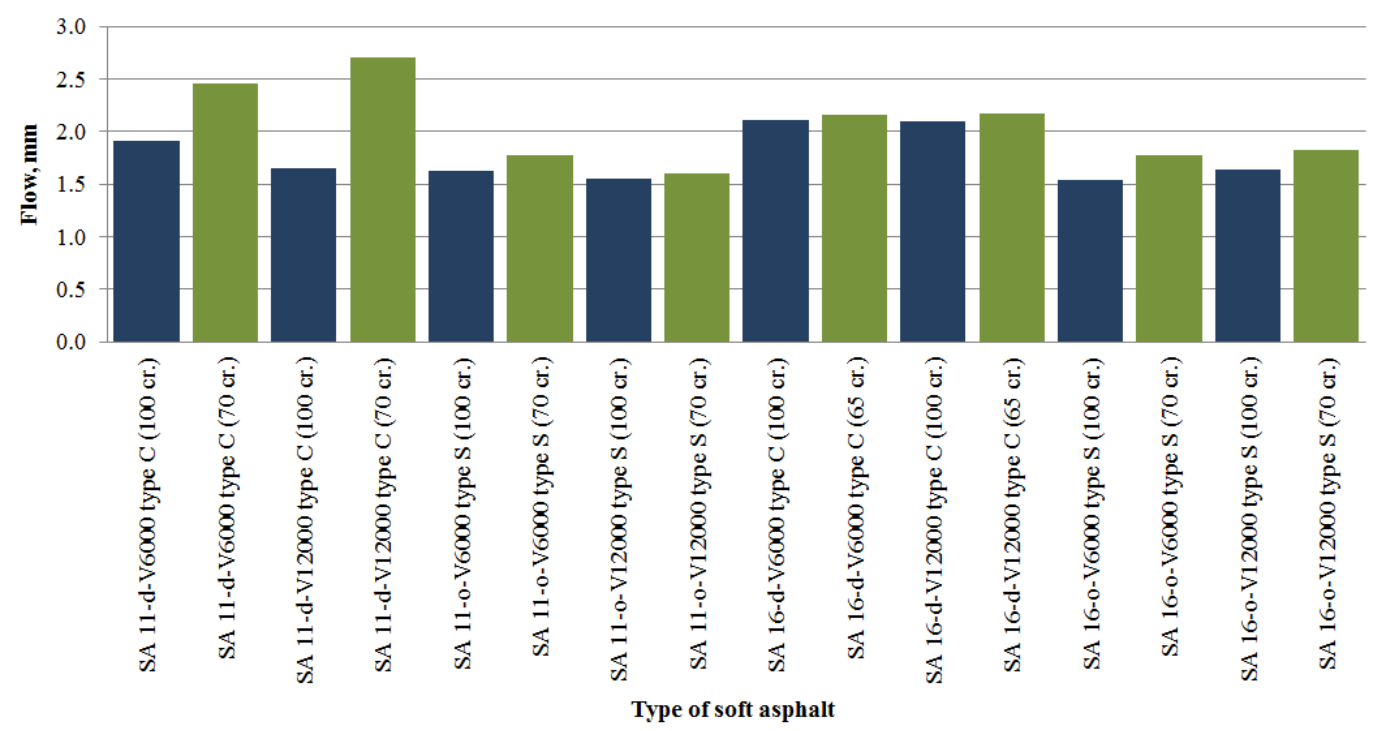

Fig. 2. Flow of soft asphalt

Results of Marshall test showed that the flow varies from $1.5 \mathrm{~mm}$ (SA 11-o-V12000 type S (100 cr.)) to $2.7 \mathrm{~mm}$ (SA 11-dV12000 type C (70 cr.)) (Fig. 2). The flow of soft asphalt mixtures, in which the aggregate was made of $100 \%$ crushed particles, is lower than of the mixtures in which the aggregate was made of $\leq 70 \%$ of crushed particles. Comparing soft asphalt mixtures of type $\mathrm{C}$ and $\mathrm{S}$, it was determined that the flow of soft asphalt mixture of type $\mathrm{C}$ is higher than that of soft asphalt mixture of type S. Studying the relationship between the flow of soft asphalt mixtures and the type of bituminous binder it was determined that the difference in the results between soft asphalt mixtures with the bituminous binder V6000 or V12000 is insignificant.

Fig. 3 gives the results of indirect tensile strength test of soft asphalt mixtures. 


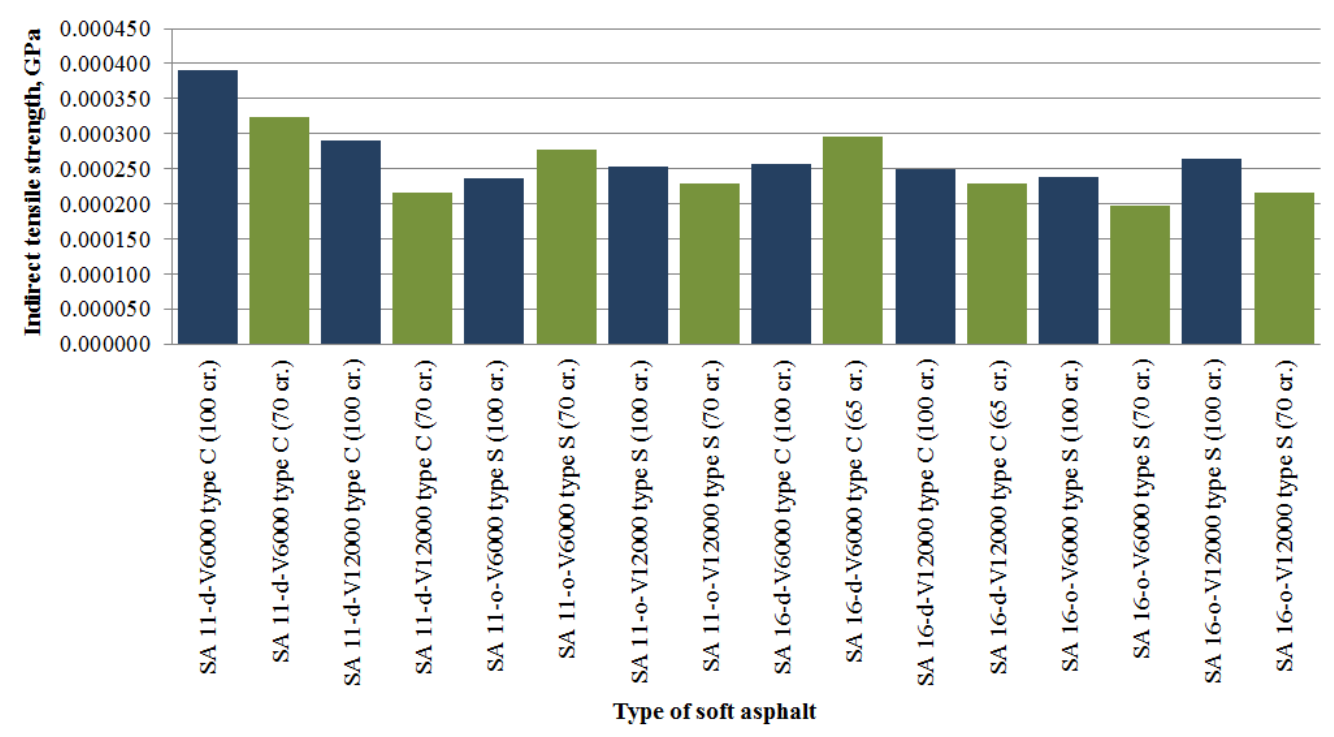

Fig. 3. Indirect tensile strength of soft asphalt

The highest indirect tensile strength $(0.000324 \mathrm{GPa})$ was determined in the specimens of SA 11-d-V6000 type C $(100 \mathrm{cr}$.), the lowest $(0.000198 \mathrm{GPa})$ - in the specimens of SA 16-0-V6000 type S $(70 \mathrm{cr}$.). It was determined that the indirect tensile strength decreases if the aggregates of soft asphalt mixture are made of less than $70 \%$ of crushed particles. With the exception of two soft asphalt mixtures, i.e., SA 11-o-V6000 type S and SA 16-d-V6000 type C, where the indirect tensile strength has increased when using less than $70 \%$ of crushed particles.

Fig. 4 gives the results of water sensitivity test of soft asphalt mixtures.

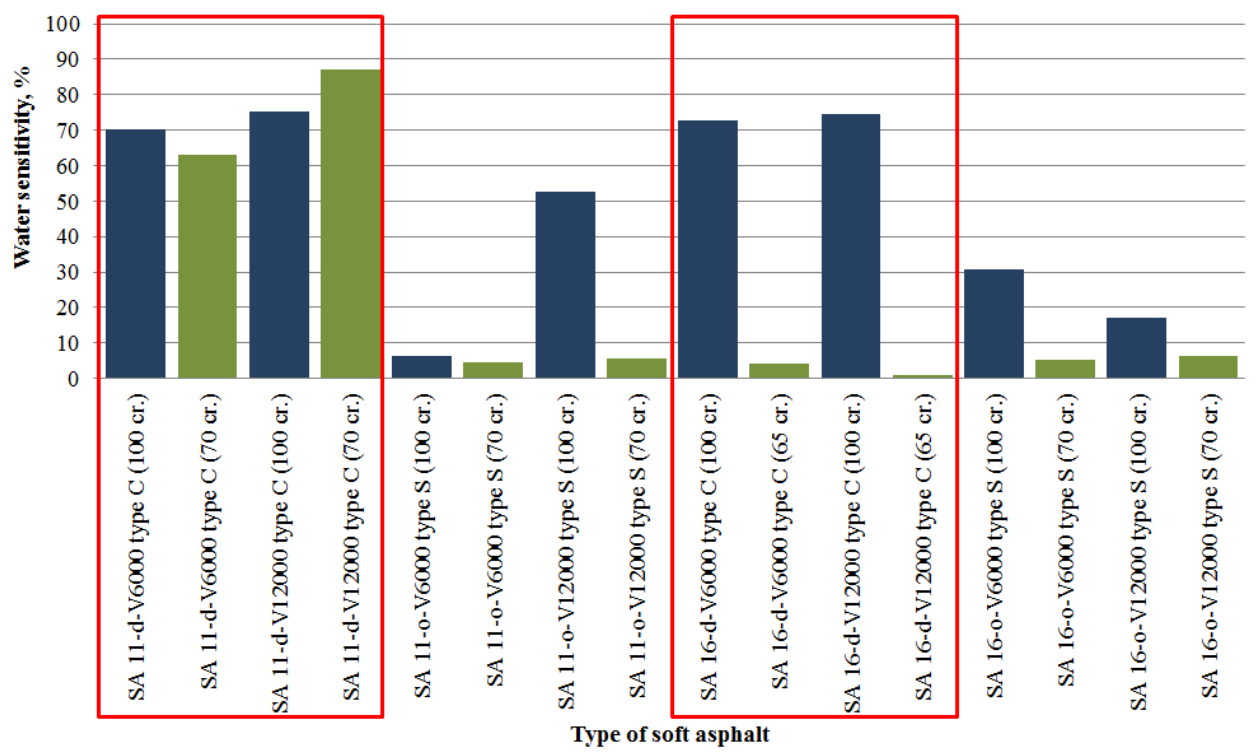

Fig. 4. Water sensitivity of soft asphalt

The test showed that there is no direct relationship between the type of soft asphalt mixture (type C and S), the content of crushed particles in the aggregate and the type of bituminous binder. Only soft asphalt mixtures of type C can be marked out in which the ratio of indirect tensile strength is higher than $60 \%$, except the mixtures SA 16-d-V6000 type C (65 cr.) and SA 16-d-V12000 type C (65 cr.) in which the ratio of indirect tensile strength is lower than $5 \%$. The ratio of indirect tensile strength of soft asphalt mixture of type $\mathrm{S}$ varies from $0.9 \%$ to $30.6 \%$ where a rather large dispersion of results was also identified.

Analysis of the results of experimental tests of soft asphalt mixtures showed that the best results of mechanical tests were obtained in the specimens of soft asphalt mixture of type C. Comparing results by the binder type the better results were obtained in those specimens of soft asphalt mixture of type $\mathrm{C}$ in which the bituminous binder V6000 was used. The results of mechanical tests worsen if the mineral material mixture of soft asphalt mixture is made of less than $70 \%$ of crushed particles. 
Laboratory results, obtained by the testing of properties mentioned above, were summarized and assessed using one of the most widely used multi-criteria evaluation methods - the SAW method. This method allows choosing rational project solutions comparing several options [11]. The coefficient of rationality according to this method was calculated and presented in the in Fig. 5.

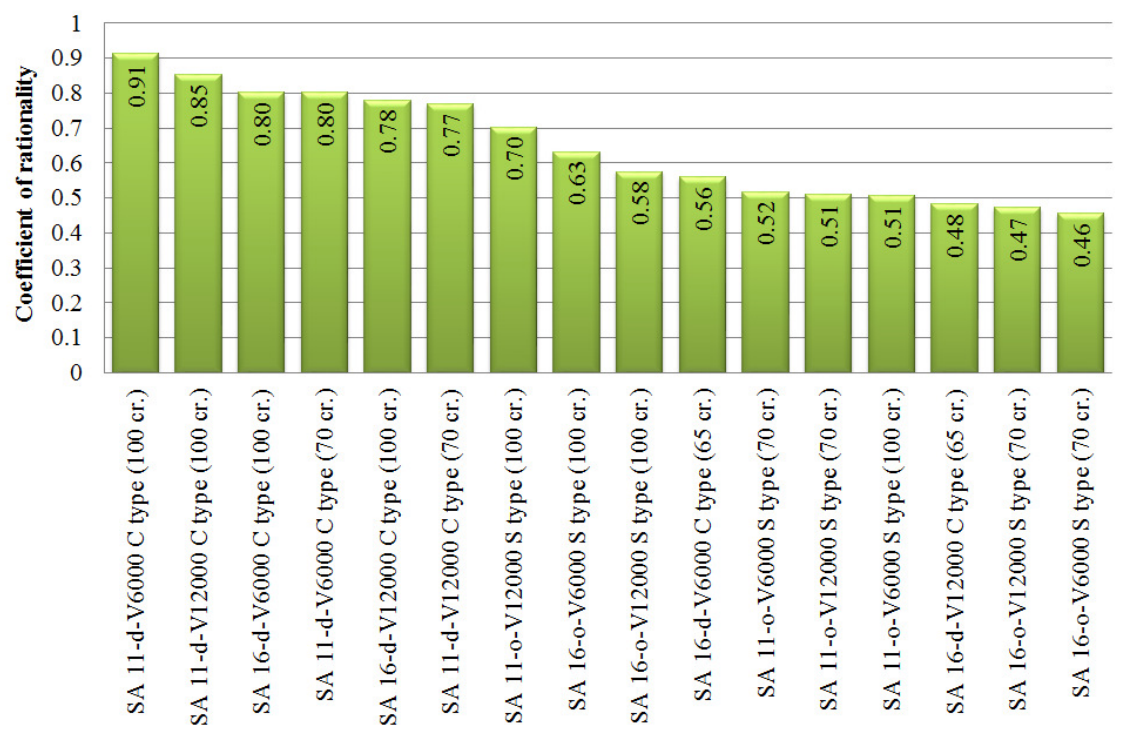

Fig. 5. Coefficient of rationality of soft asphalt

The distribution of soft asphalt mixtures was determined calculating the coefficient of rationality by the SAW method. The top four mixtures with the coefficient of rationality $\geq 0.8$ are as follows:

- SA 11-d-V6000 C type (100 cr.);

- SA 11-d-V12000 C type (100 cr.);

- SA 16-d-V6000 C type (100 cr.);

- SA 11-d-V6000 C type (70 cr.).

The experience of using asphalt pavements in Lithuania showed that the most suitable fraction of aggregates for the asphalt pavement-base (single wearing and base course layer) courses is the fraction $0 / 16$. Therefore, based on the analysis performed it was recommended SA 16-d-V6000 type C soft asphalt reconstructing low-volume roads with gravel pavement.

\section{Recommendations for soft asphalt pavement structure}

When designing soft asphalt pavement structure, the reference was made to "the General Technical Specifications for Roads - Chapter 3 - Pavement Design", issued by the Swedish National Road Administration. The pavement structure was adapted to the regional climatic conditions, frost index, soil type and traffic loads. Finally, in a combination with Lithuanian "Technical Specifications for the Standardized Road Pavement Structures", the soft asphalt pavement structure, given in Fig. 6, was derived.

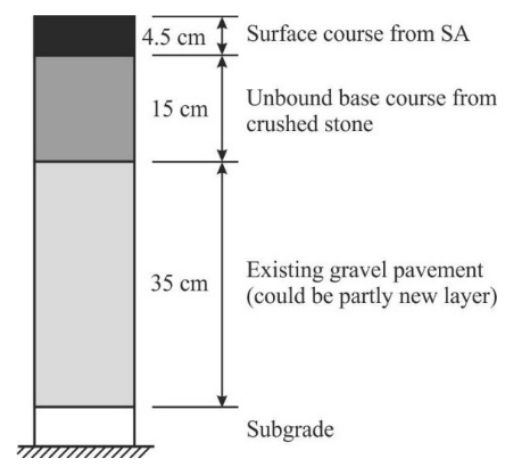

Fig. 6. The structure of soft asphalt pavement

Also, the main characteristics of structure of reconstructed low-volume road were recommended:

- annual average daily traffic (AADT) $-\leq 500 \mathrm{vpd}$;

- allowable number of $10 \mathrm{t}$ standard axle loads $-\leq 100000$;

- bearing capacity of the subgrade $-\geq 45 \mathrm{MPa}$; 
- bearing capacity of the unbound base course $-\geq 120 \mathrm{MPa}$.

The aggregates, unbound mixtures and their layer properties shall comply with the requirements of European standards and national specifications.

\section{Conclusions}

In the laboratory there were designed and mixed 16 different soft asphalt mixtures using different granular composition of aggregates, type of soft bitumen and ratio of crushed and round particles. It was determined that the stability of soft asphalt mixtures, in which the aggregate was made of $100 \%$ of crushed particles, is $9 \%$ higher than that of the same type of soft asphalt mixture in which the aggregate was made of $\leq 70 \%$ of crushed particles. The flow of soft asphalt mixtures, in which the aggregate was made of $100 \%$ crushed particles, is $12.5 \%$ lower than of the mixtures in which the aggregate was made of $\leq 70 \%$ of crushed particles. The indirect tensile strength decreases if the mixture of mineral materials of soft asphalt mixture is made of less than $70 \%$ of crushed particles.

Also, it was determined that there is no direct relationship between the type of soft asphalt mixture (type C and S), the content of crushed particles in the aggregate and the type of bituminous binder. Only soft asphalt mixtures of type C can be marked out in which the ratio of indirect tensile strength is higher than 60\%, except the mixtures SA 16-d-V6000 type C (65 cr.) and SA 16-d-V12000 type C (65 cr.) in which the ratio of indirect tensile strength is lower than 5\%.

The best results of mechanical tests were obtained in the specimens of soft asphalt mixture of type C. Comparing results by the binder type, the better results were obtained in those specimens of soft asphalt mixture of type $\mathrm{C}$ in which the bituminous binder V6000 was used.

Based on the analysis performed, SA 16-d-V6000 type C soft asphalt was recommended for reconstruction of lowvolume roads with gravel pavement.

Also, the soft asphalt pavement structure was recommended which is adapted to the regional climatic conditions, frost index, soil type and traffic loads.

\section{References}

[1] Lithuanian Road Administration. General Information. The Ministry of Transport and Communications, Republic of Lithuania, Vilnius http://www.lra.lt. Accessed January 24, 2013.

[2] Žilionienè, D.; Čygas, D.; Juzènas, A. A.; Jurgaitis, A. 2007. Improvement of Functional Designation of Low-volume Roads by Dust Abatement in Lithuania, Journal of the Transportation Research Board 1989: 293-298. http://dx.doi.org/10.3141/1989-34

[3] Gintalas, V. 2010. Possibilities for the Improvement of the Quality of Design Solutions in the Gravel Road Reconstruction Projects, The Baltic Journal of Road and Bridge Engineering 5(3): 177-184. http://dx.doi.org/10.3846/bjrbe.2010.25

[4] Vorobjovas, V. 2011. Assurance of The Function of Low-volume Roads for the Improvement of Driving Conditions, The Baltic Journal of Road and Bridge Engineering 6(1): 67-75. http://dx.doi.org/10.3846/bjrbe.2011.09

[5] Žilionienè, D.; Vorobjovas, V. 2011. Correspondence of Horizontal and Vertical Alignment with Safe Driving Conditions on Low-volume Roads, Journal of the Transportation Research Board 2203: 49-56. http://dx.doi.org/10.3141/2203-06

[6] Dell'Acqua, G.; De Luca, M.; Russo, F. 2012. Procedure for Making Paving Decisions with Cluster and Multicriteria Analysis, Journal of the Transportation Research Board 2282: 57-66. http://dx.doi.org/10.3141/2282-07

[7] Safwat, S. 2000. Cold Technique of Asphalt Paving. Swedish National Road and Transport Research Institute VTI.

[8] Jacobson, T. 2001. Cold Recycling of Asphalt Pavement-Mix in Plant. Swedish National Road and Transport Research Institute VTI.

[9] Jacobson, T.; Hakim, H.; Safwat, S. 2006a. Undersokning av mekaniska egenskaper hos tunna belaggningar av MJAB, Etapp I [Analysis of Mechanical Properties of Soft Asphalt MJAB, the 1st Stage]. Swedish National Road and Transport Research Institute VTI.

[10] Jacobson, T.; Hakim, H.; Safwat, S. 2006b. Utvardering av massabelaggning med mjukgjord bitumen, MJAB och MJAG, Etapp II [Evaluation of Properties of Asphalt Mixtures MJAB and MJAG with Modified Bitumen, the 2nd Stage]. Swedish National Road and Transport Research Institute VTI.

[11] Mitkus, S.; Dejus, T. 1999. Kiekybiniai tyrimu metodai [Quantitative Research Methods]. Vilnius, 1999. 